\title{
Remembering from any angle: The flexibility of visual perspective during retrieval
}

\author{
Heather J. Rice ${ }^{\mathrm{a}, *}$, David C. Rubin ${ }^{\mathrm{b}, \mathrm{c}}$ \\ ${ }^{a}$ Department of Psychology, Washington University, St. Louis, MO, United States \\ ${ }^{\mathrm{b}}$ Department of Psychology and Neuroscience, Duke University, Durham, NC, United States \\ ${ }^{\mathrm{c}}$ Center on Autobiographical Memory Research, Aarhus University, Aarhus, Denmark
}

\section{A R T I C L E I N F O}

\section{Article history:}

Received 6 February 2010

Available online 24 November 2010

\section{Keywords:}

Autobiographical memory

Imagery

Visual perspective

Field perspective

Observer perspective

Retrieval

\begin{abstract}
A B S T R A C T
When recalling autobiographical memories, individuals often experience visual images associated with the event. These images can be constructed from two different perspectives: first person, in which the event is visualized from the viewpoint experienced at encoding, or third person, in which the event is visualized from an external vantage point. Using a novel technique to measure visual perspective, we examined where the external vantage point is situated in third-person images. Individuals in two studies were asked to recall either 10 or 15 events from their lives and describe the perspectives they experienced. Wide variation in spatial locations was observed within third-person perspectives, with the location of these perspectives relating to the event being recalled. Results suggest remembering from an external viewpoint may be more common than previous studies have demonstrated.
\end{abstract}

(c) 2010 Elsevier Inc. All rights reserved.

Individuals often re-experience visual images when remembering events (Brewer, 1988). For example, remembering a lecture given to a group of students, a person might visualize himself or herself lecturing from the students' perspective. Such images are thought to be integral to autobiographical memory retrieval; individuals with damage to visual cortex not only develop visual memory deficits, but also exhibit impaired recall of autobiographical memories (Greenberg \& Rubin, 2003; Rubin \& Greenberg, 1998). Visual imagery also predicts the degree to which individuals recollect previous events (Rubin, Schrauf, \& Greenberg, 2003). Remembering visual details helps one judge if an event occurred rather than having been imagined (e.g., Johnson, 1988). Imagery also plays an important role in clinical disorders such as posttraumatic stress disorder (PTSD) and depression (e.g., Holmes \& Hackmann, 2004; Reynolds \& Brewin, 1999). Visual imagery is not only critical to autobiographical retrieval processes, but can also influence behavior (e.g., Libby, Shaeffer, Eibach, \& Slemmer, 2007).

One salient aspect of these visual images is their perspective. The example above illustrates a third-person perspective in which the event is viewed from an external vantage point. In contrast, one could experience a first-person perspective in which the event is visualized from the viewpoint experienced at encoding. This distinction has a distinguished history (Freud, 1899/1953; Henri \& Henri, 1896); however, few researchers examined the topic until it was revived by Nigro and Neisser (1983). Since then a growing literature has shown perspective can influence both the phenomenology, or conscious experience, and the content of recall (see Rice, 2010, for review). For instance, first-person perspective memories are rated as more emotionally intense than third-person perspective memories (Berntsen \& Rubin, 2006; Robinson \& Swanson, 1993). Using third-person perspective also leads the rememberer to generate more details related to one's appearance, actions, and the environmental context of an event, whereas using first-person perspective produces more feelings, sensations,

\footnotetext{
* Corresponding author. Address: Department of Psychology, Washington University, Campus Box 1125, St. Louis, MO, United States. Fax: +1 314935 7588.

E-mail address: hrice@wustl.edu (H.J. Rice).
} 
and thoughts from the event (McIsaac \& Eich, 2002). Perspective has been associated with attributions of past behavior (Frank \& Gilovich, 1989) and can influence assessments of self-change (Libby, Eibach, \& Gilovich, 2005).

Given this, relatively little is actually known about third-person perspective. Consider the distinction between first-person and third-person perspectives provided by Nigro and Neisser (1983). First-person images are those in which "the scene appears from one's own position... from roughly the field of view that was available during the original situation," whereas in third-person images "one seems to have the position of an onlooker or observer, looking at the situation from an external vantage point" (pp. 467-468). Within this framework, the classification of third-person perspectives rests only on images not being first person. This leaves open the question of where the observer is located in third-person perspectives. Nigro and Neisser also raised this issue, asking participants to indicate "the position from which the scene [was] being observed" (p. 470), but did not report these data. The current study examined whether the location from which third-person perspectives are constructed varied across space or was limited to one particular viewpoint. Because this is the first study we are aware of that tries to provide an account of where the third person is in autobiographical memory, the initial analyses are often descriptive. There are no empirical findings from studies of memory to guide predictions; however, data and theory on visuospatial imagery can help.

Existing evidence suggests the construction of third-person perspectives may be flexible (i.e., constructed from varied locations). When instructed, individuals can construct different third-person images of a room in which they are currently sitting (Blackmore, 1987). Although these transformations do not require autobiographical memory, they suggest third-person perspectives are flexible. Studies of visuospatial imagery also demonstrate that individuals can adopt different viewpoints of an environment (see Zacks \& Michelon, 2005 for review). These studies differ from autobiographical memory studies in several ways; yet, the ability to manipulate imagery to take different viewpoints suggests individuals may be able to construct a range of third-person perspectives.

Theoretical explanations of perspective use also support this hypothesis. Clark and Wells (1995) proposed that socially anxious individuals construct third-person images as a means of visualizing how they look to others. If true, perspective location may vary in concordance with the location of other individuals present during encoding, suggesting third-person perspectives should not be limited to a single location. Others have hypothesized that third-person images allow individuals to distance themselves from events, serving as a defense mechanism to prevent the re-experiencing of emotions (e.g., Berntsen, Willert, \& Rubin, 2003; McIsaac \& Eich, 2004) or as a means of emotion-regulation (Kross, Ayduk, \& Mischel, 2005). In other words, adding physical distance within the image from the person remembering (i.e., a third-person perspective) produces an emotional distance. It is possible that individuals use greater physical distances to produce greater emotional distance. This would require that the distance of images from an individual's original location vary. Again, this would require third-person perspectives not be limited to a single location.

The data collected to date are silent on this issue. The focus of the current study was to characterize if and how third-person perspectives vary. Our first step then was to demonstrate clearly that third-person locations vary. Moreover, it was important to show systematic variations in location, to ensure more than random noise produces the variation. We used a sample of arbitrary, but distinct, situations (Nigro \& Neisser, 1983). These events varied across two dimensions, emotional intensity and self-awareness. It was expected that these events would produce a range of third-person locations because the two hypotheses that locations may vary highlight the role of emotional intensity and self-awareness. Of primary interest was investigating the distribution of perspective locations and replicating differences in location across two samples using slightly different procedures. If variation is established, an entirely new set of questions will arise, such as why some locations are favored and if these locations have specific functions. However, before addressing such questions, we must demonstrate that variation occurs and can be measured in a consistent manner.

\section{Study 1}

A novel technique was used in which participants were asked to describe the perspective accompanying each memory rather than use a Likert-type scale, as in prior studies. Ten memories were cued with events adapted from Nigro and Neisser (1983). In addition, five memories were cued with time periods, different aspects of which are reported here and elsewhere (Rice \& Rubin, 2009).

\subsection{Method}

\subsubsection{Participants}

Eighty-six Duke University undergraduates (51 females; mean age $=18.90$ ) were tested individually or in small groups.

\subsubsection{Materials and procedure}

Participants completed three temporally contiguous phases (Table 1). In Phase 1, participants were told they would be recalling events. The experimenter then read aloud a description of perspective to participants as they read along. The description provided concrete examples of perspectives one might use when recalling an event, including first-person and a few third-person perspectives. Participants were then given examples of how to describe the relative location of their perspective in relation to their original location during the event. For example, remembering giving a lecture from a students' 
Table 1

Order of tasks in Studies 1 and 2

\begin{tabular}{clll}
\hline & Phase 1 & Phase 2 & Phase 3 \\
\hline $\begin{array}{c}\text { Study 1 (tested via } \\
\text { paper and pencil } \\
\text { packet) }\end{array}$ & Perspective instructions & $\begin{array}{l}\text { Cue presented, nominated memory, described } \\
\text { perspective, rated phenomenology }(15 \times)\end{array}$ & $\begin{array}{l}\text { Categorized perspective } \\
(15 \times)\end{array}$ \\
$\begin{array}{c}\text { Study 2 (tested via } \\
\text { computer) }\end{array}$ & $\begin{array}{l}\text { Cue presented and } \\
\text { nominated memory } \\
(10 \times)\end{array}$ & Perspective instructions & $\begin{array}{l}\text { Described perspective, } \\
\text { rated phenomenology } \\
(10 \times)\end{array}$ \\
\hline
\end{tabular}

perspective, one might describe the perspective as being directly in front of the original location, $20 \mathrm{ft}$ away, and below eye level. Participants were told that if they experienced multiple perspectives, they should describe them all and demarcate their dominant perspective (see Appendix A for complete instructions).

In Phase 2, participants were presented with 15 cues, in pseudo-randomized order, and described the perspective of their image. Ten cues were specific events adapted from Nigro and Neisser (1983, Table 2) and five were time periods (i.e., before elementary school, during elementary school, during middle school, during high school, and during college). Participants also answered questions about phenomenology.

In Phase 3, participants categorized the description of their dominant perspective for each event. This required participants to narrow down their perspective in terms of spatial location provided by the experimenter. For the height dimension, the options were seeing the event from one's own eye level, from slightly above one's own head, from ceiling height, from above ceiling height, from the eye level of a child, or from floor level. For the spatial location, options were from one's own eyes, from directly in front and facing one's self, from directly behind one's self, from the left and behind, from the right and behind, from the left and in front, from the right and in front, from directly to the left, and from directly to the right. Fifty participants also categorized the distance of their perspective. This included the following options: from one's own eyes, $3 \mathrm{ft}$ away or closer, 3-6 ft away, 6-20 ft away, 20-100 ft away, and $100 \mathrm{ft}$ away or more. Each distance dimension was accompanied by a short description to help participants accurately determine the approximate distance. For example, the $20-100 \mathrm{ft}$ option read " $20-100 \mathrm{ft}$ away (100 ft is approximately the length of a college basketball court)."

\subsection{Results}

A total of 1260 memories were obtained due to missing data for 30 memories. To examine the overall proportion of firstand third-perspective memories, two independent coders coded participants' perspective descriptions (Phase 2) and discrepancies were resolved by HJR. Participants described 65\% of their dominant perspectives as third person. This percentage is higher than in previous studies, which typically find fewer third-person than first-person perspectives, even when using very similar events (Nigro \& Neisser, 1983).

The location of third-person images were plotted according to participants' categorization (from Phase 3) using four dimensions: (1) distance, (2) locations in front of or behind the individual or from the body plane passing directly from the right to the left of the individual, (3) height, and (4) locations to the left or the right of the individual or from the body plane passing from directly in front to behind the individual. Because of the focus on characterizing third-person perspectives, memories with dominant first-person perspectives were removed from this and later analyses. Non-dominant perspectives were not available because participants were not asked to categorize them.

Notably, a range of third-person locations was reported rather than a single, or few, locations (Fig. 1a). Thus, third-person perspective locations do vary across spatial locations. The second question of interest was to determine if third-person

Table 2

Chi-square and phi for comparisons across events and dimensions for Study 1 (S1) and Study 2 (S2).

\begin{tabular}{|c|c|c|c|c|c|c|c|c|c|c|c|c|c|c|c|c|}
\hline \multirow{3}{*}{ Event } & \multicolumn{4}{|c|}{ Distance dimension } & \multicolumn{4}{|c|}{ Front/back dimension } & \multicolumn{4}{|c|}{ Height dimension } & \multicolumn{4}{|c|}{ Side/body dimension } \\
\hline & \multicolumn{2}{|l|}{ S1 } & \multicolumn{2}{|l|}{ S2 } & \multicolumn{2}{|l|}{$\mathrm{S} 1$} & \multicolumn{2}{|l|}{ S2 } & \multicolumn{2}{|l|}{ S1 } & \multicolumn{2}{|l|}{ S2 } & \multicolumn{2}{|l|}{$\mathrm{S} 1$} & \multicolumn{2}{|c|}{$\mathrm{S} 2$} \\
\hline & $\chi^{2}$ & $\Phi$ & $\chi^{2}$ & $\Phi$ & $\chi^{2}$ & $\Phi$ & $\chi^{2}$ & $\Phi$ & $\chi^{2}$ & $\Phi$ & $\chi^{2}$ & $\Phi$ & $\chi^{2}$ & $\Phi$ & $\chi^{2}$ & $\Phi$ \\
\hline Being in an accident & $4.80^{*}$ & .40 & 2.46 & .31 & 3.66 & .19 & $14.48^{* *}$ & .54 & $14.64^{* *}$ & .37 & $9.77^{*}$ & .43 & .02 & .02 & 1.00 & .20 \\
\hline Demonstrating skill & $18.78^{* *}$ & .72 & .68 & .14 & $6.38^{*}$ & .23 & 2.17 & .17 & 4.67 & .19 & 3.30 & .21 & $7.00^{*}$ & .33 & $7.11^{*}$ & .44 \\
\hline Group performance & $7.04^{*}$ & .39 & $3.79^{*}$ & .32 & $59.15^{* *}$ & .66 & $28.17^{* *}$ & .63 & 1.09 & .09 & 3.53 & .22 & $4.76^{*}$ & .26 & 1.78 & .22 \\
\hline Having conversation & $12.80^{* *}$ & .80 & $14.73^{* *}$ & .82 & 1.50 & .14 & 1.45 & .18 & $11.17^{* *}$ & .39 & 4.45 & .32 & 1.00 & .17 & .18 & .09 \\
\hline Individ. presentation & .00 & .00 & .64 & .13 & $76.10^{* *}$ & .78 & $41.69^{* *}$ & .73 & 5.65 & .21 & 2.00 & .16 & 1.61 & .16 & $4.33^{*}$ & .33 \\
\hline Running for exercise & .03 & .03 & .04 & .04 & 2.58 & .15 & 2.38 & .21 & $22.81^{* *}$ & .44 & $10.89^{* *}$ & .45 & .15 & .05 & .62 & .15 \\
\hline Running from threat & .00 & .00 & .12 & .06 & $6.68^{*}$ & .23 & $7.09^{*}$ & .33 & $24.12^{* *}$ & .43 & $16.65^{* *}$ & .49 & .14 & .05 & .76 & .15 \\
\hline Studying & $11.76^{* *}$ & .59 & $21.78^{* *}$ & .78 & $9.24^{*}$ & .28 & $8.00^{*}$ & .33 & $43.59^{* *}$ & .61 & $9.50^{*}$ & .36 & .28 & .07 & .11 & .06 \\
\hline Swimming & .42 & .11 & .23 & .08 & $8.86^{*}$ & .27 & 5.54 & .28 & $31.71^{* *}$ & .50 & 2.92 & .19 & .40 & .08 & .03 & .03 \\
\hline Watching news & $8.33^{* *}$ & .56 & $11.56^{* *}$ & .68 & .82 & .09 & 4.16 & .29 & $14.59^{* *}$ & .38 & $7.28^{*}$ & .38 & .18 & .06 & 3.24 & .36 \\
\hline
\end{tabular}

$p<.05$.

$p<.005$. 
A

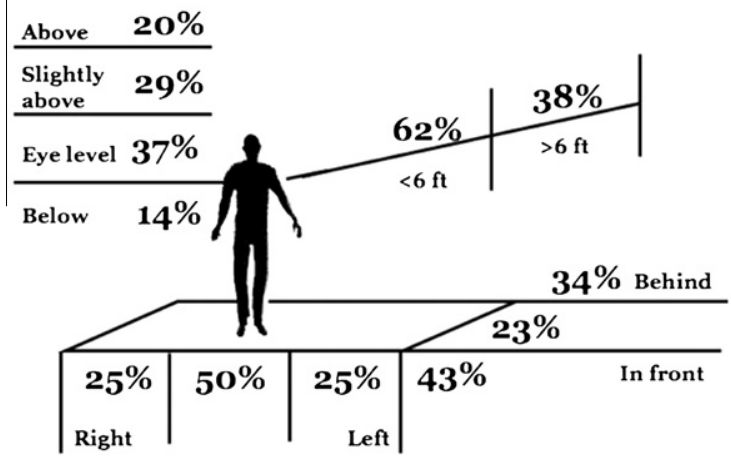

B

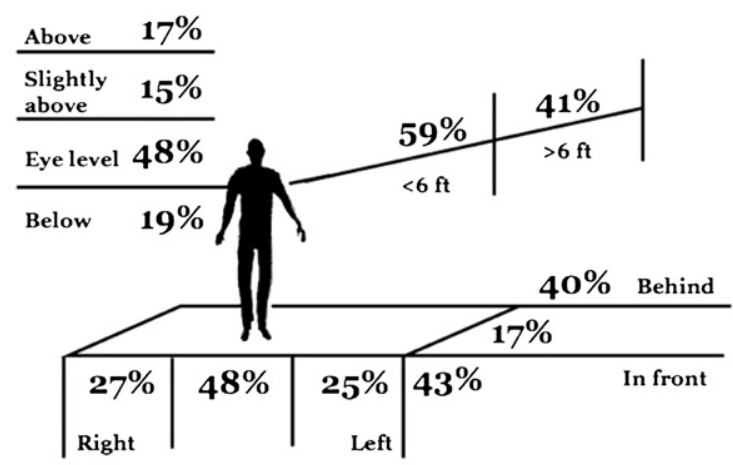

Fig. 1. Distribution of third-person perspectives across Studies 1 (panel A) and 2 (panel B). Study 1 includes data from five time periods and 10 specific events.

perspectives varied across events. To examine this the frequency with which particular locations were reported for each event were divided within the four spatial dimensions as follows: "near" (less than $6 \mathrm{ft}$ ) versus "far" (greater than $6 \mathrm{ft}$ ) dimension (or distance dimension), "in front of" versus "from body plane" versus "behind" dimension (or front/back dimension), (3) "eye level" versus "above eye level" versus "below eye level" dimension (or height dimension), (4) "to either side" versus "from body plane" dimension (or side/body dimension). These dimensions were examined for each of the 10 events. For example, for memories of studying, a chi-square was performed to examine the frequency of perspectives along the distance dimension; separate chi-square tests examined the front/back dimension, height dimension, and side/body dimension. This was repeated for all 10 events. Significance was set at .005 (i.e., .05/10 events) to control for multiple comparisons within each spatial dimension. Memories cued using time periods were excluded because the nature of the events was not interpretable based on participants' descriptions.

This analysis revealed differences in perspective location across the four dimensions and 10 events. Chi-square and phi values are presented in Table 2. These chi-square tests show that, for some events, the frequency with which individuals used a particular location during retrieval differed from the expected frequencies of an equal number of memories at each location (see Figs. 2-4 for proportions).

Examining the distance dimension, several events led to more perspectives from near the individual. These included having a conversation $\left(\chi^{2}(1, N=20)=12.80, \Phi=.80\right)$, demonstrating a skill $\left(\chi^{2}(1, N=36)=18.78, \Phi=.72\right)$, studying $\left(\chi^{2}(1, N=34)=11.76, \Phi=.59\right)$, and watching the news $\left(\chi^{2}(1, N=27)=8.33, \Phi=.56\right)$. Differences were also observed across the front/back dimension, such that memories of giving an individual presentation $\left(\chi^{2}(2, N=62)=76.10, \Phi=.78\right)$ and being in a group performance $\left(\chi^{2}(2, N=68)=59.15, \Phi=.66\right)$ led to memories from in front of the individual. Locations differed across the height dimension, such that memories of having a conversation $\left(\chi^{2}(2, N=36)=11.17, \Phi=.39\right)$ and watching the news $\left(\chi^{2}(2, N=51)=14.59, \Phi=.38\right)$ led to more perspectives originating from eye level than expected by chance, whereas memories for running for exercising $\left(\chi^{2}(2, N=59)=22.81, \Phi=.44\right)$, being in an accident $\left(\chi^{2}(2, N=53)=14.64\right.$, $\Phi=.37)$, running from a threat $\left(\chi^{2}(2, N=65)=24.12, \Phi=.43\right)$, swimming $\left(\chi^{2}(2, N=63)=31.71, \Phi=.50\right)$, and studying $\left(\chi^{2}(2, N=58)=43.59, \Phi=.61\right)$ led to more perspectives from above the individual. There were no significant chi-square tests within the side/body dimension.

Although these significant chi-square tests do not indicate that there was a statistical difference in location across events, there were quantitative discrepancies in the proportion of memories constructed from locations in the distance, front/back, and height dimensions. For example, the proportion of memories coming from within $6 \mathrm{ft}$ was three times larger for face-toface conversations than group performances and from in front of themselves was three times larger for individual presentations than demonstrating a skill.

Together, these results support the notion that third-person perspectives vary across events and are not limited to a particular location in space for three of the four dimensions measured. However, to ensure that these differences were reliable and not simply due to random noise, we replicated these results in a second study.

\section{Study 2}

Results from Study 1 demonstrated that individuals can construct third-person perspectives from a range of locations rather than being limited to a few locations and provided preliminary evidence that the event being remembered influences third-person perspective locations. To show that these results were reliable and the differences in proportions across events were not due to random noise, we replicated the study. It was also important to replicate the results given the novelty of the findings and given that participants described more third-person perspectives than reported in previous studies.

Additionally, one possible critique of Study 1 was that giving participants a description of perspective prior to event cues might bias the memories being nominated. To address this, participants were asked to nominate events prior to the 


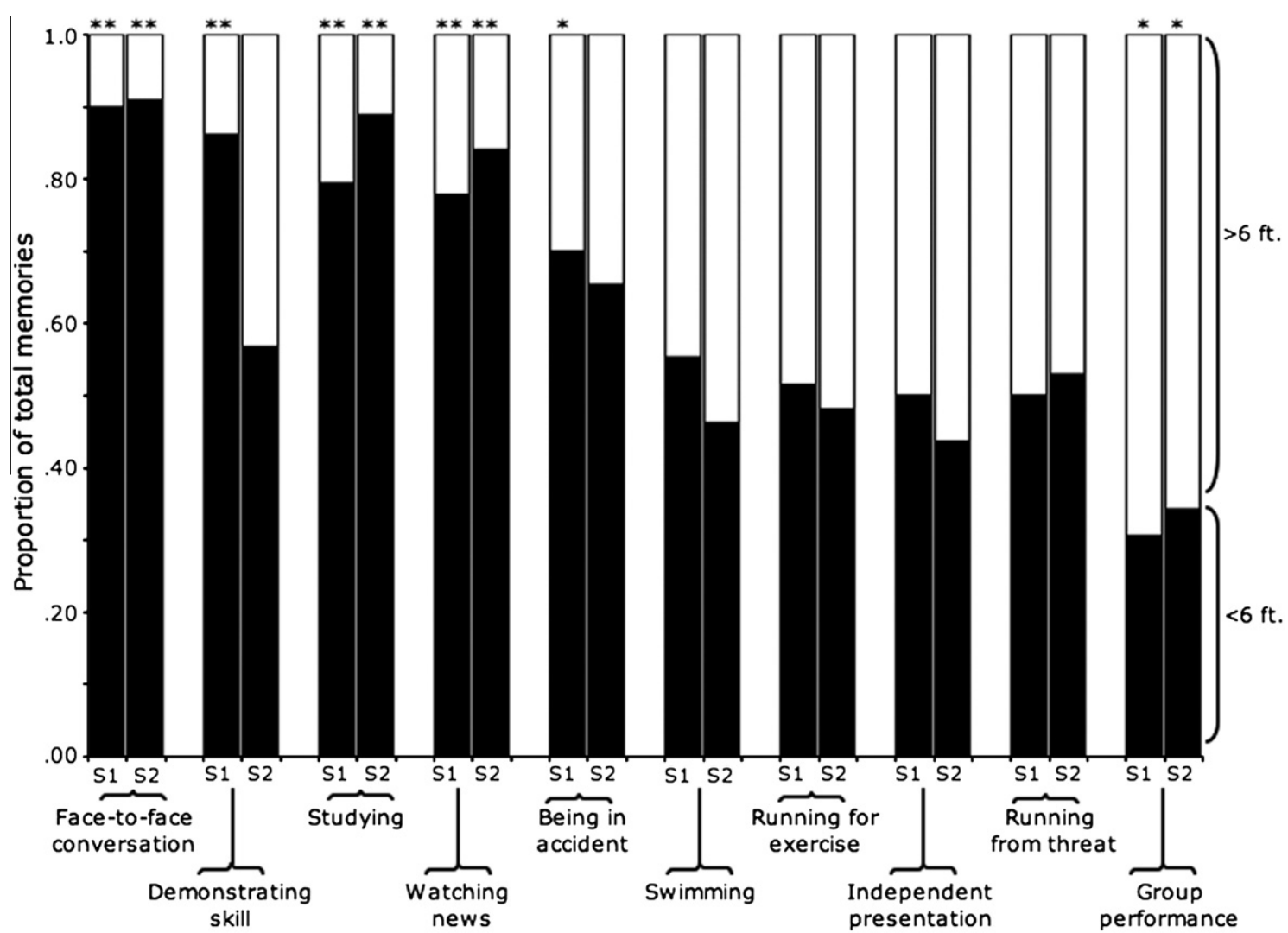

Fig. 2. Proportion of third-person perspectives located less than $6 \mathrm{ft}$ and greater than $6 \mathrm{ft}$ away from the individual in Studies 1 (S1) and 2 (S2). Events are organized using data from Study 1, ordering events from those most often experienced from less than $6 \mathrm{ft}$ to events experienced least often from less than 6 ft. ${ }^{*} p<.05,{ }^{* *} p<.005$.

introduction of the concept of visual perspective in Study 2. The experiment was also completed on computer, rather than via paper and pencil.

\subsection{Method}

\subsubsection{Participants}

Fifty-one Duke University undergraduates (34 females; mean age $=19.06$ ) were tested individually or in small groups.

\subsubsection{Materials and procedure}

Participants completed four temporally contiguous phases (Table 1), which were presented via computer using the program DirectRT (Jarvis, 2002). In Phase 1, participants were presented with the 10 event cues from Study 1. They were instructed to press a button once they retrieved a specific memory and to type a short description to serve as a cue throughout the experiment. In Phase 2, they were presented with the same description of perspective provided in Study 1. Several photographs that had been taken of an individual sitting in the participant's location (i.e., sitting at a computer in our laboratory testing room) accompanied this description. These photographs were taken from several positions around the computer in order to illustrate the concept of visual perspective and help participants understand how to describe their own perspectives. In Phase 3, participants described as many perspectives as they experienced, typing their dominant perspective first. They also answered questions about phenomenology from the Autobiographical Memory Questionnaire (Rubin et al., 2003). In Phase 4, participants were presented with their perspective descriptions and asked to categorize them along the same dimensions used in Study 1 with one small change; the option "from waist height" was used for the height dimension instead of "eye level of a child."

\subsection{Results}

A total of 503 memories were obtained due to missing data for seven memories. Based on participants' descriptions (Phase 3), 64\% of dominant perspectives came from third-person perspective. This percentage is almost identical to Study 1 even though the order of tasks differed. 


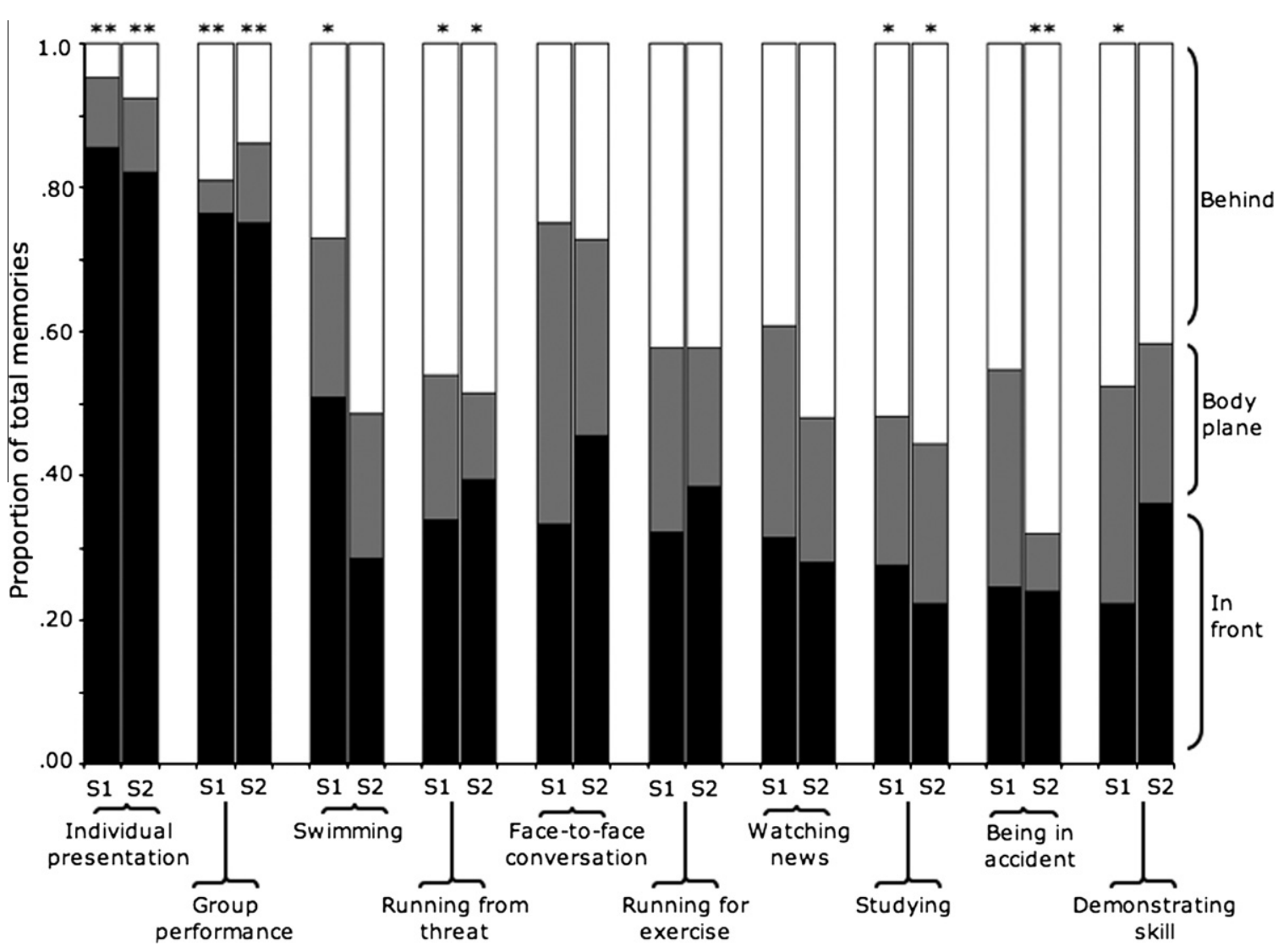

Fig. 3. Proportion of third-person perspectives located in front of, from the body plane, or behind the individual in Studies 1 (S1) and 2 (S2). Events are organized using data from Study 1, ordering events from those most often experienced from in front of the body to events experienced least often from in front of the body. ${ }^{*} p<.05,{ }^{* *} p<.005$.

Based on participants' categorizations (Phase 4), the distribution of third-person perspectives was plotted as in Study 1 (Fig. 1b). This revealed very similar results to Study 1, and, again, illustrates that third-person perspectives come from a range of locations. To examine regularity in perspective location across the 10 event types, the four categorized dimensions were examined separately for each event, as in Study 1. Data are presented in Figs. 2-4. Chi-square and phi values for all comparisons are presented in Table 2.

Examining the distance dimension, several events led to more perspectives from near the individual. These included having a conversation $\left(\chi^{2}(1, N=22)=14.73, \Phi=.82\right)$, studying $\left(\chi^{2}(1, N=36)=21.78, \Phi=.78\right)$, and watching the news $\left(\chi^{2}(1, N=25)=11.56, \Phi=.68\right)$. These findings are consistent with those from Study 1 . Differences were also observed across the front/back dimension, such that memories of giving an individual presentation $\left(\chi^{2}(2, N=39)=41.69, \Phi=.73\right)$ and being in a group performance $\left(\chi^{2}(2, N=28.17)=, \Phi=.63\right)$ led to images from in front of the individual, consistent with findings from Study 1. Being in an accident also led to images from behind the individual $\left(\chi^{2}(2, N=25)=14.48, \Phi=.54\right)$. Locations differed across the height dimension, such that memories of running for exercising $\left(\chi^{2}(2, N=27)=10.89, \Phi=.45\right)$ and running from a threat $\left(\chi^{2}(2, N=34)=16.65, \Phi=.49\right)$ led to more perspectives from eye level. As with Study 1 , there were no significant chi-square tests within the side/body dimension.

\subsubsection{Reliability across Studies 1 and 2}

The primary motivation for completing Study 2 was to examine the consistency of locations across studies. Examining the significant effects across the two studies, there were 13 significant chi-square tests in Study 1 and eight significant chisquare tests in Study 2. Seven of the eight significant chi-square tests in Study 2 were also significant in Study 1: in the distance dimension, having a face-to-face conversation, studying and watching the news, in the front/back dimension, giving an independent presentation and being in a group performance, and in the height dimension, running for exercise and running from a threat. For each of the seven chi-square tests, the proportion of memories originating from each location is quite similar across the two studies. This regularity is one indication that the differences in location across events is real and not due to random variation.

To statistically examine consistency, chi-square tests comparing perspective locations across the two studies were calculated for each event and each of the four spatial dimensions. A significant chi-square test would indicate dependency 


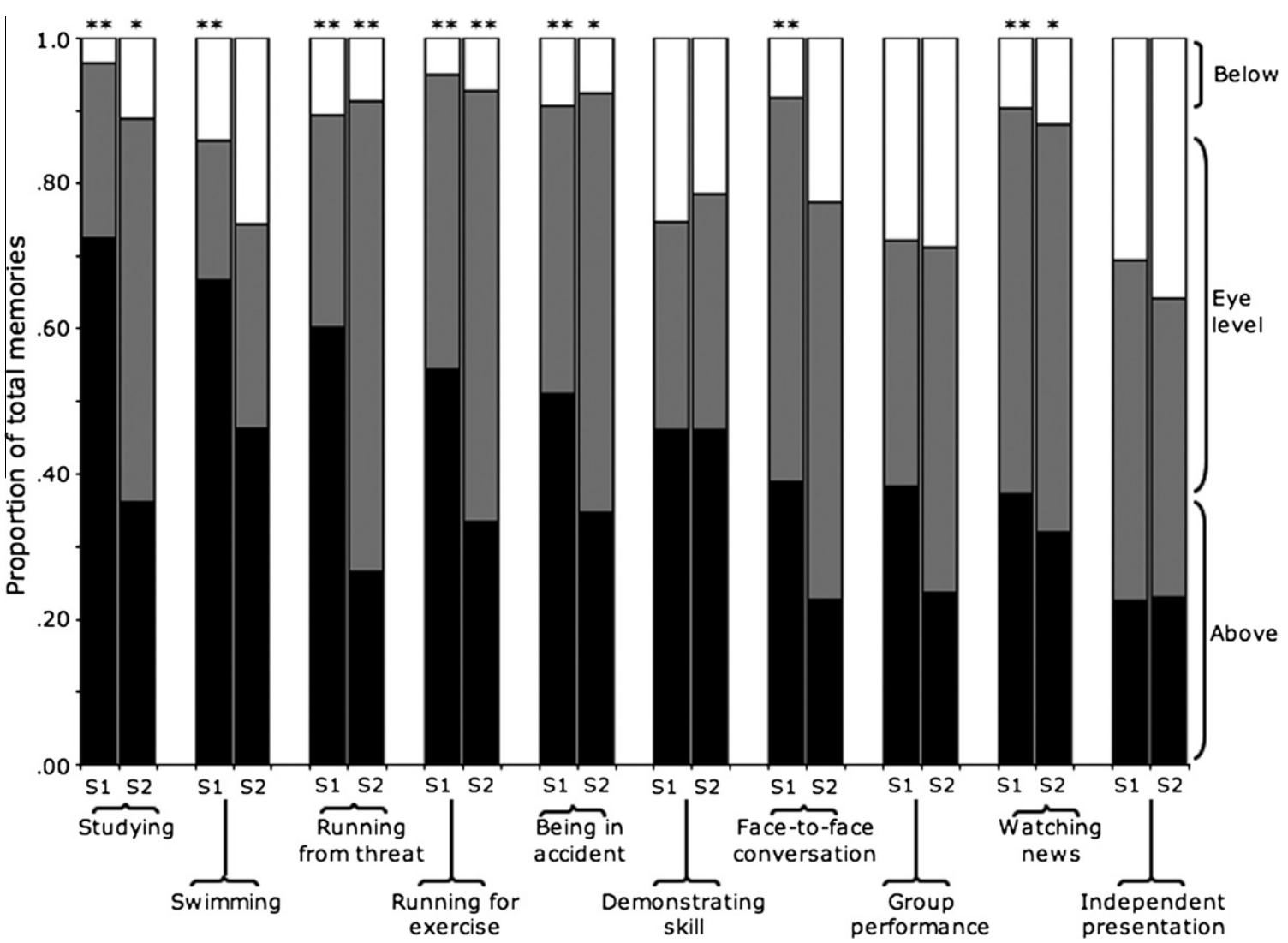

Fig. 4. Proportion of third-person perspectives located above, from eye level, or below the individual in Studies 1 (S1) and 2 (S2). Events are organized using data from Study 1, ordering events from those most often experienced from above to events experienced least often from above. ${ }^{*} p<.05$, ${ }^{* *} p<.005$.

between study and location (i.e., the proportion of individuals experiencing an event from a particular location would depend on both the study and the location). Thus, a greater number of significant chi-square tests reflects less consistency. A $p$-value of .005 was used to control for the 10 multiple comparisons within each dimension. Only two significant differences were observed across experiments, both within the height dimension: studying, $\chi^{2}(2, N=94)=12.24, p=.0022$, $\Phi=.36$, and running from a threat, $\chi^{2}(2, N=99)=12.04, p=.0024, \Phi=.35$. The limited number of significant differences across the two studies further demonstrates that our technique produces replicable results, even when the order of study phases was manipulated across the two studies.

The strongest evidence that the results replicate over two independent samples and are not just random variation is the correlations taken over the 10 events for each of the categories of our four dimensions. Specifically, each event was treated as a data point $(N=10)$ and the proportions for each spatial location was correlated across the two studies. For example, the proportion of memories recalled from less than $6 \mathrm{ft}$ away for each event was correlated across Studies 1 and 2. Statistically, the 10 events are not independent because there may be effects of rating one event on another, but such effects do not affect the argument that the 10 events differ in the location of their preferred third-person perspective. This issue was further minimized by the fact that the order of events differed across the two studies.

In general, these correlations were quite high, accounting for more than half the variation in the proportion of participants selecting each location. Most were in the range one would expect for replications of a standardized test over two administrations. In particular, the correlations were: distance dimension of more or less than $6 \mathrm{ft}, r(8)=.85, p=.0018$ (assuming the events are independent); front/body dimension - in front, $r(8)=.89, p=.0006$, body plane, $r(8)=.64$, $p=.0463$, behind, $r(8)=.83, p=.0029$; height dimension - above, $r(8)=.56, p=.0923$, eye level, $r(8)=.41, p=.2393$, below, $r(8)=.82, p=.0036$; side/body dimension, $r(8)=.81, p=.0045$. The extremely high magnitude of most of the correlations reinforces the reliability of the findings across Studies 1 and 2.

\subsection{Discussion}

Using a novel technique to measure perspective, in which individuals described rather than rated their experience of perspective, this is the first study to demonstrate that individuals can construct third-person perspectives from a range of spatial locations during autobiographical memory retrieval, without prompts or instructions to construct a particular third-person perspective. Some locations were experienced more often than others. Perspectives from in front of the 
individual were more common than those from behind. Those near the individual were more common than those from more than $6 \mathrm{ft}$ away. It was also uncommon for individuals to report perspectives from below eye level, which is consistent with a study asking individuals to construct viewpoints of a room in which they were sitting (Blackmore, 1987); perspectives from foot-level were more difficult to construct than those anchored at eye level or above the head.

In addition, results showed that the location from which third-person perspectives are constructed is related to the event being recalled in a reliable manner. For example, remembering a face-to-face conversation produced images from near the individual, whereas remembering a group performance produced images from a distance. Remembering giving an individual presentation produced memories from in front of the individual, whereas remembering being in an accident produced memories from behind the individuals. Given the format of our data (i.e., repeated measures with a categorical dependent variable), we were unable to directly compare the proportions from each event to all other events. However, the reliability of the findings across Studies 1 and 2 indicate that the quantitative differences between events are real and not due to random variation. Thus, third-person perspective locations are indeed related to the event being recalled. This is the first study to show that third-person perspective locations vary and that they vary according to the events being recalled.

An interesting pattern emerged when examining the predominant location used for each event. In several cases perspective location corresponded with the likely location of other individuals. Memories of running from a threat tended to come from behind the individual, whereas performing in front of others, either as a group or individually, produced memories from in front of the individual. Height and distance dimensions also seemed to correspond to the location of others with memories of a conversation anchored at eye level and nearby, whereas memories of swimming were anchored above the individual. However, this convention does not explain the predominant perspective location for all events. For example, it is unclear why memories of swimming would come from in front of an individual or memories of demonstrating a skill from behind. The hypothesis that the location of others influences perspective location could not be directly tested in this data set given that information about where other individuals were located during the events was not obtained. Future studies should examine this hypothesis.

An alternative explanation is that individuals construct images from locations they have experienced in the past. For instance, when watching others in a group performance, an individual typically tends to view the event from a distance and in front of those performing, which corresponds to the third-person perspective associated with that event. It is possible that the perspective of images, like other aspects of memory, are influenced by schematic knowledge. However, preliminary data from our laboratory suggests this is not the case (Rice, 2007). Using the same events used here, participants were asked indicate the optimal location from which to watch someone else complete each activity, as well as where others would watch one's self complete each activity. These locations did not correspond with the locations accompanying memories reported in Studies 1 and 2.

We also found evidence that third-person perspective memories may be more common than suggested by previous studies (e.g., Robinson \& Swanson, 1993), even those using similar events (Nigro \& Neisser, 1983). We suggest two possible explanations for this discrepancy. First, providing a more detailed description of third-person perspectives than previous studies may bias individuals to construct more of them. Given this, why were such detailed descriptions used? Pilot data suggested that without this additional detail, participants had difficulty understanding the task. Rather than describing their perspective, many participants provided descriptions that were vague and did not include perspective information (e.g., I see a church). Thus, the detail provided was necessary in order to obtain codable data. A second explanation is that asking participants to be very specific about the location of their perspective may prompt them to categorize perspectives that would otherwise be considered first-person as third person. Thus, asking for a fine-grained description of perspective may capture individuals' phenomenological experience more precisely and accurately. Additional research is necessary to distinguish between these two possible alternatives. Regardless of the outcome, our results suggest that this method for measuring perspective is both effective and reliable given the replication of findings across experiments and the ability to replicate the finding that recalling remote memories produces more third-person perspectives than recent memories.

These findings have interesting implications for studies of visual perspective in memory and provide promising links to other disciplines. For example, if third-person perspectives vary in location, do they vary in other ways? Given that perspective may be used as an emotional regulation strategy (Kross et al., 2005), it is possible that memories recalled from near an individual would be more vivid or emotionally intense than those recalled from a distance. Future studies should examine these possibilities; for example, asking individuals to use a particular third-person perspective and examining the effect of these perspectives on phenomenology. Holmes et al. (2008) found that imagining events using a first-person perspective produces a more positive mood than using a third-person perspective. Future studies could examine this effect using different third-person perspectives. The links between perspective, imagery, mood, and emotion (see Holmes \& Hackmann, 2004 for several articles related to imagery and clinical disorders) could have important implications for the treatment of several clinical disorders and is a quickly growing area of research (see Rice, 2010, for review of perspective and relation to imagery, emotion, and disorders).

The current findings also suggest perspective may be influenced by the location of other individuals, providing some support for the notion that perspective is used as a way of visualizing how one appears to others (e.g., Clark, 2001; Clark \& Wells, 1995). Future research should investigate this possibility by experimentally manipulating the location of individuals during event encoding and examining the influence on perspective location at retrieval. An understanding of how third-person perspective locations vary may provide insight into the function of perspective. 
The possibility that third-person locations correspond to the location of others during encoding of the event suggests visual perspective may also provide a connection to perspective-taking literatures. Perspective-taking can refer to the literal viewpoint one takes, in which an individual visualizes how an environment looks to another (e.g., Galinsky, Magee, Inesi, \& Gruenfel, 2006; Piaget \& Inhelder, 1956). It can also refer to an individuals' ability to imagine how another person perceives, feels, or interprets an event (e.g., Davis, 1983; Galinsky et al., 2006). Given that when individuals experience a third-person perspective in memory, they tend to construct their viewpoint from the location of other individuals, it may be that this ability is related to perspective-taking ability. Recent evidence from neuroimaging suggests that similar brain regions are engaged when projecting oneself in time (i.e., the past or the future) and space (i.e., different perspectives), supporting this potential link between visual perspective and perspective-taking (Buckner \& Carroll, 2007). Future studies should examine the relationship between visual perspective in memory and perspective-taking. For example, does the ability to take different perspectives in memory develop along with perspective-taking in the environment and social perspective-taking abilities?

Taken together, these findings provide evidence that there is no single third-person perspective location. Rather, individuals can construct these perspectives from many locations and the location can be affected by the event being remembered. Asking individuals to describe their perspective is an effective means of measuring perspective and also provides an innovative way to examine the role visual perspective plays in memory retrieval and a range of related disciplines.

\section{Acknowledgments}

The authors thank Dorthe Berntsen, Rachel Cohen, Kathleen McDermott, Roddy Roediger, Karl Szpunar, Cindy Wooldridge, and members of the Roediger lab reading group for helpful comments, the National Institute of Mental Health (Grant Number R01 MH066079) for funding, and Karen Burns, Ricky Green, Tiffany Udoh, and other research assistants for entering and coding data. Portions of this paper were presented at the Psychonomics Conference in Houston, TX and the American Psychological Society Convention in Los Angeles, CA.

\section{Appendix A. Instructions from Study 1}

In this study we are trying to find out about properties of autobiographical memories, or personal memories for past events. On the following pages, you will find descriptions of several events. For each description we will ask you to recall a memory for a specific event in your life, to think about it for a while, and then to answer questions about that memory. There are no correct answers; we are just trying to document the kinds of memories people have.

Many of the questions will ask you about the way you visualize these events. When remembering an event from the past, many people find they construct a visual image of the experience. For example, if a person remembers the last time he talked with his mother, he might experience a visual image the scene, including the clothes his mother was wearing, her location within the room, and objects within the surrounding environment.

These visual images can originate from various locations within the overall scene. For example, a person might visualize his mother as he saw her during the original event, in which he visualizes her as though standing directly in front of her and imaging only the objects directly behind her. Or he might visualize the event from above, as though floating above the room or near the ceiling, in which he can "see" the entire environment, perhaps including himself. Or he might visualize the event as though he were standing beside his mother and himself, in which he visualizes both of them from the side.

The first question will ask you to indicate from where you visualize each event. We would like you to use yourself as the anchor point of the image. Therefore, please indicate the origin of the image in relation to yourself during the initial event (e.g., above and behind your head, to the left of yourself and above, out of your own eyes, directly in front of yourself, etc.). Please be sure you describe the relative location, relative height, and relative distance from yourself during the original event.

Some people find that the origin of their image seems to change. If you find this to be the case, please use the additional blanks to describe the other origin locations. Place a star next to the perspective that seems to be most dominant and use this perspective when answering questions about your dominant perspective.

Finally, if you have any questions, please feel free to ask.

\section{References}

Berntsen, D., \& Rubin, D. C. (2006). Emotion and vantage point in autobiographical memory. Cognition and Emotion, 20, $1193-1215$.

Berntsen, D., Willert, M., \& Rubin, D. C. (2003). Splintered memories or vivid landmarks? Qualities and organization of traumatic memories with and without PTSD. Applied Cognitive Psychology, 17, 675-693.

Blackmore, S. J. (1987). Where am I? Perspectives in imagery and the out-of-body experience. Journal of Mental Imagery, 11, 53-66.

Brewer, W. F. (1988). Memory for randomly sampled autobiographical events. In U. Neisser \& E. Winograd (Eds.), Remembering reconsidered: Ecological and traditional approaches to the study of memory (pp. 21-90). Cambridge: Cambridge University Press.

Buckner, R. L., \& Carroll, D. C. (2007). Self-projection and the brain. Trends in Cognitive Science, 11, 49-57.

Clark, D. M. (2001). A cognitive perspective on social phobia. In W. R. Crozier \& L. E. Alden (Eds.), Social phobia - diagnosis, assessment, and treatment (pp. 405-430). Chichester: John Wiley \& Sons.

Clark, D. M., \& Wells, A. (1995). A cognitive model of social phobia. In R. G. Heimberg, M. Liebowitz, D. A. Hope, \& F. Schneier (Eds.), Social phobia: Diagnosis, assessment, and treatment. New York: Guilford. 
Davis, M. H. (1983). Measuring individual differences in empathy: Evidence for a multidimensional approach. Journal of Personality and Social Psychology, 44, $113-126$.

Frank, M. G., \& Gilovich, T. (1989). The effect of memory perspective on retrospective causal attributions. Journal of Personality and Social Personality, 57, $399-403$.

Freud, S. (1899). The complete psychological works of Sigmund Freud (Vol. 3). London: The Hogarth Press Limited.

Galinsky, A. D., Magee, J. C., Inesi, M. E., \& Gruenfel, D. H. (2006). Power and perspectives not taken. Psychological Science, $17,1068-1074$.

Greenberg, D. L., \& Rubin, D. C. (2003). The neuropsychology of autobiographical memory. Cortex, 39, 687-728.

Henri, V., \& Henri, C. (1896). Enquete sur les premier souvenirs de l'enfance. L'Annee Psychologique, 3, 187-198.

Holmes, E. A., Coughtrey, A. E., \& Connor, A. (2008). Looking at or through rose-tinted glasses? Imagery perspective and mood. Emotion, 8, 876-879.

Holmes, E. A., \& Hackmann, A. (2004). Mental imagery and memory in psychopathology. Memory, 4 (Special Issue).

Jarvis, B. (2002). DirectRT (Version 2002 4.0.1). New York: Empirisoft.

Johnson, M. K. (1988). Reality monitoring: An experimental phenomenological approach. Journal of Experimental Psychology: General, 117, $390-394$.

Kross, E., Ayduk, O., \& Mischel, W. (2005). When asking “why” does not hurt. Distinguishing rumination from reflective processing of negative emotions. Psychological Science, 16, 709-715.

Libby, L. K., Eibach, R. P., \& Gilovich, T. (2005). Here's looking at me: The effect of memory perspective on assessments of personal change. Journal of Personality E Social Psychology, 88, 50-62.

Libby, L. K., Shaeffer, E. M., Eibach, R. P., \& Slemmer, J. A. (2007). Picture yourself at the polls: Visual perspective in mental imagery affects self-perception and behavior. Psychological Science, 18(3), 199-203.

McIsaac, H. K., \& Eich, E. (2002). Vantage point in episodic memory. Psychonomic Bulletin E Review, 9, 146-150.

McIsaac, H. K., \& Eich, E. (2004). Vantage point in traumatic memory. Psychological Science, 15, $248-253$.

Nigro, G., \& Neisser, U. (1983). Point of view in personal memories. Cognitive Psychology, 15, 467-482.

Piaget, J., \& Inhelder, B. (1956). The child's conception of space. London: Routledge \& K. Paul.

Reynolds, M., \& Brewin, C. R. (1999). Intrusive memories in depression and posttraumatic stress disorder. Behaviour Research and Therapy, 37, 201-215.

Rice, H. J. (2007). Measuring visual perspective in autobiographical memory across time periods and events. Unpublished doctoral dissertation, Duke University.

Rice, H. J. (2010). Seeing where we're at: A review of visual perspective and memory retrieval. In J. H. Mace (Ed.), The act of remembering: Toward an understanding of how we recall the past. Wiley-Blackwell.

Rice, H. J., \& Rubin, D. C. (2009). I can see it both ways: First- and third-person visual perspectives at retrieval. Consciousness $\mathcal{E}$ Cognition, 18, 877-890.

Robinson, J. A., \& Swanson, K. L. (1993). Field and observer modes of remembering. Memory, 1, 169-184.

Rubin, D. C., \& Greenberg, D. L. (1998). Visual memory-deficit amnesia: A distinct amnesic presentation and etiology. Proceedings of the National Academy of Sciences USA, 95, 5413-5416.

Rubin, D. C., Schrauf, R. W., \& Greenberg, D. L. (2003). Belief and recollection of autobiographical memories. Memory E Cognition, 31, 887-901.

Zacks, J. M., \& Michelon, P. (2005). Transformations of visuospatial images. Behavioral and Cognitive Neuroscience Reviews, $4,96-118$. 